\title{
Differences in Managing Anticoagulants and Antiplatelets for Gastrointestinal Endoscopy between East and West
}

\author{
Sun-Young Lee
}

\begin{abstract}
Decreasing the bleeding risk associated with gastrointestinal (GI) endoscopic procedures and minimizing the thromboembolic risk of withdrawing medications are very important for the patients taking anticoagulants and antiplatelets. Western guidelines on managing anticoagulation and antiplatelet medications in GI endoscopy suggest a polypectomy with aspirin medication or a biopsy with warfarin medication. However, Eastern endoscopists' adherence to Western guidelines may be responsible for Easteners experiencing massive bleedings. During the cessation of drugs, it should be emphasized that Asians may be predisposed to different forms of embolism more likely to be of the cerebrovascular system, whereas Westerners more likely to be of the cardiovascular variety. To better understand the differences between the East and West, differences in drug metabolism should be considered that results in greater body weight-normalized plasma unbound clearance of drug in Easterners. Taken as a whole, different managements are required for GI endoscopy in patients on anticoagulation and/or antiplatelet medications based on differences in metabolism of drugs, risk of hemorrhage, and forms of thromboembolism.
\end{abstract}

Keywords: Anticoagulation; Antiplatelet; Endoscopy; East; West

\section{Introduction}

Anticoagulants and antiplatelets may potentiate gastrointestinal (GI) bleeding due to medication, thromboem-

\footnotetext{
Manuscript accepted for publication April 8, 2009.

Department of Internal Medicine, Konkuk University School of Medicine, 4-12 Hwayang-dong, Gwangjin-gu, Seoul 143-729, South Korea.

E-mail: sunyoung@kuh.ac.kr
}

bolism related to interruption of medication for endoscopic procedure, and bleeding after endoscopic procedure. A recent international survey has shown that there is a wide variation between the Eastern and Western endoscopists in managing anticoagulants and antiplatelets during the periendoscopic period [1]. This might be based on the differences in education, guidelines, genetics, environments, risk factors (diabetes mellitus, hypertension, hyperlipidemia, and obesity), prevalence of cardiovascular attack (stroke, deep vein thrombosis, and ischemic heart disease), effectiveness and side effects of antiplatelets or anticoagulants. For example, Eastern endoscopists frequently experience severe bleeding while following Western guidelines (ie, for a polypectomy with aspirin medication or a biopsy with warfarin medication) [2-5], and thus recent Eastern publications recommend withdrawing either antiplatelets or anticoagulants even for a biopsy [6-8]. Unfortunately, little is known about rationales on such differences between the East and West in managing antiplatelets or anticoagulants for GI endoscopy.

The aim of this review is to better understand the differences between the East and West by analyzing the: (1) East and West differences in endoscopists' conception, (2) East and West differences in complications such as hemorrhage and embolism, and (3) East and West differences in drug metabolism.

\section{Differences in endoscopists' conception between the East and West}

Given the paucity of available data on different practice patterns between the Eastern and Western endoscopists, I and my colleagues performed an international survey to the GI endoscopists in Eastern (Korea, Japan, China, India, Thailand, Singapore, Malaysia, and Philippines) and Western (United States and Canada) countries [1]. It appeared that Eastern endoscopists do not typically perform an endoscopic biopsy while their patients are on warfarin therapy and do not perform a polypectomy while their patients are taking aspirin. In addition, there was a delay ( 1 to 3 days later) on restarting medications after an endoscopic biopsy or a polypectomy only in the Easternists. This oc- 
curred despite published Western guidelines that suggest it is safe to perform an endoscopic biopsy during warfarin therapy or a polypectomy while on aspirin medication [25], and despite a published paper stated that patients treated by the American Society of Gastrointestinal Endoscopy guidelines had $0 \%$ rate of thrombosis [9]. Through our survey [1], we could find that Eastern endoscopists believe it to be dangerous to follow Western guidelines because of an increased risk of bleeding in Asian patients. It seems that personal experience is a more powerful driver of practice than the published literature for the GI endoscopists.

\section{Management of drugs for diagnostic endoscopy}

Most Eastern and Western endoscopists continued all medications when performing diagnostic endoscopy without a biopsy, and restarted it on the same day after the procedure [1]. After an endoscopic biopsy, the Eastern endoscopists tended to restart medications 1 to 3 days later, except for nonsteroidal anti-inflammatory drugs (NSAIDs) restarting on the same day, whereas the Western endoscopists restarted all medications on the same day. A recent European guideline makes the differences more definite by recommending warfarin and clopidogrel to be continued [5], while Japanese guidelines recommend cessation of aspirin and clopidogrel for low-risk procedures [6].

\section{Management of drugs for therapeutic endoscopy}

Most Eastern and Western endoscopists withdrew all medications other than NSAIDs for a polypectomy, and restarted 1 to 3 days after a polypectomy [1]. Main difference between the East and West was found on managing aspirin for a polypectomy. Eastern endoscopists tended to withdraw aspirin for more than 7 days before a polypectomy, whereas Western endoscopists performed a polypectomy without withdrawing aspirin medication. In addition, Eastern endoscopists restarted aspirin 1 to 3 days after a polypectomy, whereas Western endoscopists restarting it on the same day [1].

\section{Publications on managing antiplatelets and/or antiplatelets for endoscopy}

Great differences between the East and West were found in published articles on managing anticoagulants and antiplatelets for GI endoscopy (Table 1) [1, 2, 4-6, 8, 1015]. To explain this discrepancy, differences in effectiveness and side effects of antiplatelets and anticoagulants between the East and West should be discussed with the differences in complications such as bleeding and thromboembolism [16]. Although it is difficult to conclude the superiority, it should be reminded that life threatening bleeding is rare when compared to the risk of thromboembolism. Bleeding usually result in less morbidity and can be managed by the endoscopists, whereas major thromboembolic events during discontinuation of drugs often lead to death or permanent disability [7, 8, 17]. Cultural difference should be also considered for such difference because it might be speculated that Western gastroenterologists would limit anticoagulant abstinence for their patients, because of more litigious nature of medicine in Western societies.

Taken as a whole, racial differences in susceptibility to complications have led to establish different guidelines between countries, especially between the East and West. A large, prospective, randomized, and double-blinded clinical study might be a solution, but it is very dangerous and unethical to perform such a prospective study in patients on antiplatelets or anticoagulants. Therefore, opinion of the experts or review papers should be an alternative proposal.

\section{Differences in complications between the Easterners and Westerners}

Complications in patients on anticoagulation and/or antiplatelet medications can be divided into three categories: (1) spontaneous GI bleeding from medication; (2) GI bleeding related to an endoscopic procedure; and (3) thromboembolism from cessation of medications.

\section{Embolism}

High risks for thromboembolisms are valvular heart disease with atrial fibrillation, mechanical valve with past history of thromboembolism, and mechanical valve in mitral area [2]. Of these risk factors, atrial fibrillation is most dangerous factor that increases thromboembolic risk with older age more than 80 year-old, past or family history of cerebrovascular embolism, hypertension, congestive heart failure, diabetes mellitus, or hyperlipidemia [18].

In Western studies, it has been reported that acute coronary syndrome is not rare within one month of aspirin withdrawal [19, 20]. In contrary, it seems that Asians are more susceptible to cerebral stroke than Caucasians, whereas Caucasians are more susceptible to other cardiovascular attacks including deep vein thrombosis (Table 2) [7, 8, 17, 21-23]. Therefore, it should be emphasized again that thromboembolism affecting Westerners may be more likely to be of the cardiovascular variety, while that of Easterners may be more likely to be of the cerebrovascular variety. It should be stressed again to Eastern endoscopists, because cerebral infarction during discontinuation of the anticoagulants or antiplatelets often leads to permanent disability or death as observed in previous Eastern reports [7, 8, 17].

According to recent data on death rates from ischemic heart disease and stroke among nations, the incidence of stroke in Korea and Japan is higher than that of ischemic heart disease [24], despite rapid increasing rate of cardiovascular disease in Asian countries since 1985 [25]. However, the rise in risk factors due to westernized life style in Japan did not result in an increase in coronary heart disease mortality and morbidity like in US, even in the post-World War II 
Table 1. Published papers on managing antiplatelets and/or anticoagulants for GI endoscopy (in recent order) (Continued in next page)

\begin{tabular}{ll}
\hline $\begin{array}{l}\text { Country } \\
\text { (author, year) }\end{array}$ & Key Messages \\
\hline
\end{tabular}

Korea
(Lee SY, 2008) Eastern endoscopists do not typically perform an endoscopic biopsy while their patients are on warfarin
therapy. (Lee SY, 2008) [1]

UK

(Veitch A, 2008)

[5]

UK

(Goel A, 2007)

[10]

Israel

(Kimchi NA, 2007)

[11]

US

(Makar GA, 2006)

[12]

- Eastern endoscopists restarted medications later (1 to 3 days) than Western endoscopists after a biopsy (same day). aspirin for more than 7 days before a polypectomy, and restarted it 1 to 3 days after a polypectomy.

- Low-risk procedures can be performed during warfarin or clopidogrel intake. LMWH in high-risk conditions. should be considered during the cessation of clopidogrel in such conditions. months have passed drug-eluting coronary stent insertion.

- With regard to warfarin, $26 \%$ of the endoscopists stopped for EGD, whereas $48.7 \%$ stopped for colonoscopy.

- During warfarin intake, 21\% took biopsies as usual, while 54\% performed after checking the INR.

- Warfarin was usually stopped for 3 days. Preferred INR was below 2.0 during the endoscopic procedure.

- Aspirin can be continued for diagnostic EGD, but should be stopped 5 to 7 days before colonoscopy, spincterotomy, esophageal dilation, endoscopic ultrasound-guided biopsy, or drainage. when the cardiovascular risk is high, aspirin should be resumed within a week after the procedure.

- NSAIDs should be stopped 8 hours before any endoscopy, and be resumed 7 to 14 days after a high-risk procedure.

- Clopidogrel should be stopped 5 days before colonoscopy. to discontinue or adjust anticoagulation.
- Aspirin, ticlopidine, and ethyl icosapentate were stopped 7 days before the procedures by most of the endoscopists, whereas warfarin was stopped 4 days before the procedures.

- With regard to the drug discontinuation before the procedures, no major differences were observed between a biopsy (low-risk procedure) and endoscopic mucosal resection (high-risk procedure).

- In case of higher risk of thromboembolism during the cessation of drugs, most of the endoscopists never performed a biopsy or endoscopic mucosal resection.

- Eastern endoscopists do not perform a polypectomy while their patients are taking aspirin. They withdrew

- High-risk procedures should be done after stopping warfarin for 5 days (INR $<1.5$ ), and substituted with

- In low-risk conditions, high-risk procedures can be performed after stopping clopidogrel for 7 days. Aspirin

- In high-risk conditions, continuing aspirin and stopping clopidogrel for 7 days should be considered, if 12

- Aspirin use should be avoided for 2 weeks after polypectomy, and 10 days after spincterotomy. However,

- For low-risk procedure (e.g. diagnostic endoscopy and colonoscopy without polypectomy), there is no need

- For high-risk procedures (e.g. polypectomy and biliary sphincterotomy), an individual approach is required. This approach includes stopping oral anticoagulant therapy with or without the administration of unfractionated heparin or LMWH during which the patient's INR is in the subtherapeutic range.

- Antiplatelet therapy can be withheld for high risk procedures, but there is insufficient evidence to indicate that bleeding risk is impacted.

Note: INR, international normalized ratio; LMWH, low molecular weight heparin; EGD, esophagogastroduodenoscopy; ERCP, endoscopic retrograde cholangiopancreaticography; NSAIDs, nonsteroidal anti-inflammatory drugs. 
Table 1 (continued). Published papers on managing antiplatelets and/or anticoagulants for GI endoscopy (in recent order)

\begin{tabular}{lc}
\hline $\begin{array}{l}\text { Country } \\
\text { (author, year) }\end{array}$ & Key Messages \\
\hline
\end{tabular}

Germany Antiplatelets were usually continued before elective procedures including diagnostic EGD, colonoscopy,

- Low-risk procedures can be performed during medications.

(Naploen B, 2006) - High-risk procedures and transnasal endoscopy should be performed after the cessation of drugs.
- Colon polypectomy and endoscopic sphincterotomy could be performed without cessation of aspirin or NSAIDs.

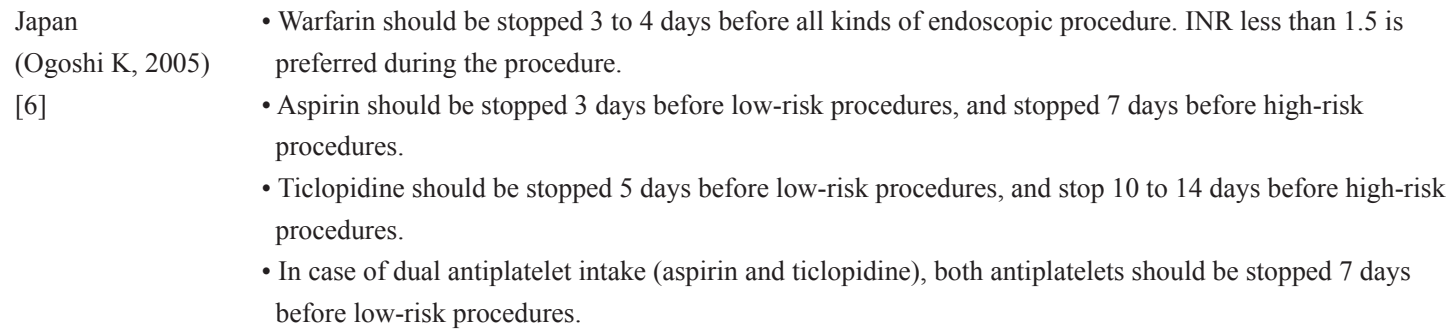
and ERCP.

- Aspirin and clopidogrel were more frequently stopped than NSAIDs prior to any endoscopic procedure.

- More than $80 \%$ stopped aspirin and clopidogrel before elective therapeutic endoscopic procedures.

- Warfarin was usually discontinued 3-5 days prior to the procedure, and was substituted with LMWH.

Belgium

(Hittelet A, 2003)

[14]

- It is not necessary to discontinue aspirin or NSAIDs for endoscopic procedures, when used in standard doses.

- It is not necessary to adjust anticoagulation for low-risk procedures, such as EGD, colonoscopy, ERCP with biopsy or stent insertion (without sphincterotomy).

- For ticlopidine or clopidogrel, it is prudent to discontinue 7 to 10 days for high-risk procedures.

- Warfarin should be discontinued 3 to 5 days before high-risk procedures.

US

(Eisen G, 2002)

[2]

- Any endoscopic procedure may be performed in patients taking aspirin or NSAIDs in the absence of preexisting bleeding disorders.

- Discontinuation of oral anticoagulation is needed for high-risk endoscopic procedures.

- Consider a heparin window only for patients with high thromboembolic risk.

- Resumption of warfarin is generally recommended at the night of the procedure except for sphincterotomy.

US

(Kadakia SC, 1996)

- Physicians stopped aspirin and NSAIDs more frequently before colonoscopy and ERCP than before EGD.

- With aspirin or NSAIDs intake, cold biopsy or hot biopsy during EGD or colonoscopy was performed, but sphincterotomy was not.

- Optimal cessation period of aspirin or NSAIDs was less than 10 days.

- Warfarin was resumed immediately after diagnostic endoscopy, whereas 7 days of cessation period was observed after therapeutic endoscopy.

Note: INR, international normalized ratio; LMWH, low molecular weight heparin; EGD, esophagogastroduodenoscopy; ERCP, endoscopic retrograde cholangiopancreaticography; NSAIDs, nonsteroidal anti-inflammatory drugs.

cohorts [25]. The ratio of ischemic heart disease to stroke is highly different between the East and West, although the prevalence of thromboembolism and their subtypes are get- ting similar throughout the world [24]. Therefore, we can speculate that genetic factor might be involved in addition to environmental factor such as westernized dietary habits 
Table 2. Reports on embolism that happened during the cessation of antiplatelets and/or anticoagulants

\begin{tabular}{|c|c|c|c|}
\hline & $\begin{array}{l}\text { Country } \\
\text { (author, } \\
\text { year) }\end{array}$ & Frequency & Type of embolism \\
\hline \multirow{3}{*}{ East } & $\begin{array}{l}\text { Korea } \\
(\text { Lee SY, } \\
2006)[17]\end{array}$ & $\begin{array}{l}\text { Six of } 81(7.4 \%) \text { endoscopists have experienced } \\
\text { embolism during past one year. }\end{array}$ & $\begin{array}{l}5 \text { cerebral infarction } \\
1 \text { mesenteric infarction }\end{array}$ \\
\hline & $\begin{array}{l}\text { Japan } \\
\text { (Ishizawa T, } \\
2006)[7]\end{array}$ & $\begin{array}{l}\text { Seven of } 81(8.6 \%) \text { endoscopists have experienced } \\
\text { embolism during past three years. }\end{array}$ & $\begin{array}{l}5 \text { cerebral infarction } \\
2 \text { myocardial infarction }\end{array}$ \\
\hline & $\begin{array}{l}\text { Japan } \\
\text { (Fujishiro M, } \\
\text { 2009) [8] }\end{array}$ & $\begin{array}{l}\text { Three of } 13(23.1 \%) \text { endoscopists have experienced } \\
\text { embolism during their career. }\end{array}$ & $\begin{array}{l}2 \text { cerebral infarction } \\
1 \text { mesenteric infarction }\end{array}$ \\
\hline \multirow{3}{*}{ West } & $\begin{array}{l}\text { US } \\
\text { (Dunn A, } \\
\text { 2003) [21] }\end{array}$ & $\begin{array}{l}\text { Twenty nine of } 1868(1.6 \%) \text { patients undergoing dental } \\
\text { or orthopedic procedures, or cataract surgery have } \\
\text { experienced thromboembolic events. }\end{array}$ & $\begin{array}{l}21 \text { cardiovascular embolism } \\
\text { including peripheral arterial } \\
\text { thromboembolism } \\
7 \text { cerebral infarction } \\
1 \text { unspecified }\end{array}$ \\
\hline & $\begin{array}{l}\text { US } \\
(\text { Garcia D, } \\
2008)[22]\end{array}$ & $\begin{array}{l}\text { Seven of } 1024(0.7 \%) \text { patients showed embolism } \\
\text { during the study period. }\end{array}$ & $\begin{array}{l}3 \text { cerebral infarction } \\
2 \text { pulmonary embolism } \\
1 \text { deep vein thrombosis } \\
1 \text { mesenteric infarction }\end{array}$ \\
\hline & $\begin{array}{l}\text { US } \\
\text { (Kuwada SK, } \\
\text { 1996) [23] }\end{array}$ & $\begin{array}{l}\text { One of } 27(3.7 \%) \text { patients showed embolism during the } \\
\text { study period. }\end{array}$ & $\begin{array}{l}1 \text { peripheral arterial } \\
\text { thromboembolism }\end{array}$ \\
\hline
\end{tabular}

(higher fat intake, lower polyunsaturated/saturated ration, and less omega-3 fatty acids). Such an ethic difference suggests that there might be some powerful and important genetic factors in Asians, and identification of such factors would clearly have great importance for prevention of cardiovascular diseases.

\section{Bleeding}

Endoscopy-induced bleeding can classified into highrisk procedures (bleeding rate $>1 \%$ ) and low-risk procedures (bleeding rate $<1 \%$ ) [2]. High-risk bleeding procedures include tissue resections such as polypectomy, mucosectomy, anpullectomy, endoscopic submucosal dissection, sphincterotomy, bougiennation, pneumatic or balloon dilation, metal stent insertion, percutaneous endoscopic gastrostomy, endoscopic ultrasonograph guided fine needle aspiration, laser ablation, photocoagulation, hemostatic procedures, and variceal ligation. According to the Western guidelines [2-5], these procedures require cessation of drug, while low-risk procedures do not. Notably, transnasal esophagogastroduo- denoscopy (EGD) should be managed as high-risk procedures because of epistaxis, whereas biliary or pancreatic stenting should be managed as low-risk procedures because of their relative safety [4].

In contrast to the outcomes of thromboembolic events from withdrawing antiplatelets and anticoagulants, hemorrhagic complications from endoscopic procedures are less likely to result in death or permanent disability. However, despite all these publications from the West, the risk of procedure-related bleeding is still heavily weighted toward the risk of a thromboembolism in the East [1]. For example, Eastern endoscopists do not follow Western guidelines (ie, for a polypectomy with aspirin medication or a biopsy with warfarin medication) because it may be responsible for patients experiencing massive bleeding $[1,6,7,8,17]$.

Anticoagulants are not by themselves ulcerogenic, but associated with a greater risk of upper GI bleeding because of an exacerbation of pre-existing lesions in the GI tract associated with NSAIDs, aspirin, or Helicobacter pylori infection [26]. Predictors of bleeding include past history of GI 
bleeding or ulcer disease, higher intensity of anticoagulation, old age more than 65 year-old, combination therapy (anticoagulants with antiplatelets), and presence of comorbid conditions like chronic renal failure, congestive heart failure, diabetes mellitus, or alcoholic liver disease [27]. Highest bleeding risk happens with warfarin followed by aspirin, NSAIDs, ticlopidine, clopidogrel, dipyridamole), and cyclooxygenase-2 (COX-2) inhibitor [28]. Of endoscopic findings, peptic ulcer is the most common, followed by hemorrhagic gastritis, and esophagitis [29].

In case of GI bleeding, complete or partial reversal of anticoagulation is undertaken based on the balance of risks between bleeding and thromboembolism. Early endoscopy can reveal lesions requiring endoscopic hemostasis, which can be performed in the setting of low-intensity anticoagulation $[29,30]$. For the hemostasis of GI bleeding during warfarin intake, partial reversal of anticoagulation to international normalized ratio (INR) 1.5 to 2.5 with fresh frozen plasma can allow for successful endoscopic hemostatic therapy [30]. Fresh frozen plasma should be used instead of vitamin K, because vitamin $\mathrm{K}$ infusion often leads to thromboembolic complication after an urgent infusion [23]. Thrombin spraying or hemoclipping could also be considered with dried human blood coagulant IX factor complex 500 unit to normalize the prolongated INR [31]. Platelet concentrate transfusion should be considered in case of antiplatelet intake, and protamine sulfate injection should be considered in case of heparin infusion.

Decision for discontinuation of drugs in the setting of GI bleeding must be made on an individual basis, based upon potential thrombotic and hemorrhagic risks. It seems prudent to briefly discontinue the drugs until lack of rebleeding, because hemodynamic instability and hemostatic changes induced by acute GI bleeding may further increase the risk of thrombosis without medications [32]. In case of longer period of cessation, low molecular weighted heparin (LMWH) should be considered instead of warfarin [33]. When it is difficult to stop aspirin, proton pump inhibitor (PPI), misoprostol, or COX-2 inhibitor should be considered [34]. In patients with a past history of peptic disease or bleeding from an acid-related lesion, PPI and H. pylori eradication should be considered to reduce the risk of upper GI bleeding even with antiplatelet intake $[32,35]$.

\section{Differences in drug metabolism between the Easterners and Westerners}

Medications that may potentiate GI bleeding has become more widespread these days (Table 3). These drugs are classified into (1) antiplatelets such as glycoprotein IIb/IIIa inhibitors, adenosine diphosphate receptor antagonist, prostaglandin analogue, COX inhibitors, etc; (2) anticoagulants such as vitamin $\mathrm{K}$ antagonists, direct thrombin II inhibitors, direct factor Xa inhibitors, heparin groups, glycosaminogly- cans, etc; (3) thrombolytic drugs/fibrinolytics; and (4) others such as non-medicinal.

\section{Warfarin}

A wide variation exists in managing warfarin before an endoscopic procedure, since the management of perioperative anticoagulation therapy for patients having a high risk of thromboembolism who are receiving long-term oral anticoagulant therapy is still uncertain. The prevalent approach is to discontinue oral anticoagulation therapy and initiate heparin therapy (Fig. 1) [36]. Another potential strategy is to continue oral anticoagulation therapy with a temporary adjustment of warfarin intensity to a preprocedural INR. For example, a Western study showed a very low risk of bleeding when clips are applied immediately after polypectomy in anticoagulated patients at high risk of thrombosis [37]. It should be emphasized that recommended INR in the West is below $2.0[2,37,38]$, while that of the East is below 1.5 for an endoscopic procedure [6].

An appropriate prothrombin time-INR seems to be lower in the Easternist than in the Westernist. INR values between 1.6 and 2.6 seem optimal to prevent ischemic or haemorrhagic events in Japanese, because bleeding complications during warfarin medication seems to be higher in Japanese [39]. An INR of 2.0 to 3.0 in Caucasians is equal to an INR of 1.6 to 2.8 in Japanese when checked by the thrombo test. It has been also reported that lower intensity warfarin (INR 1.5 to 2.1 ) treatment may be safer for the secondary prevention of stroke in Japanese patients with nonvalvular atrial fibrillation with presumed cardioembolic transient ischemic attack or stroke within the previous 6 months, than conventional-intensity (INR 2.2 to 3.5 ) warfarin treatment, because major haemorrhagic complications are avoided [40]. In this multicenter, prospective, randomized trial, optimal intensity of warfarin therapy for secondary prevention of stroke in Japanese patients with nonvalvular atrial fibrillation was INR 1.5 to 2.1, showing a lesser major hemorrhagic complication than conventional INR 2.2 to 3.5 without difference in thromboembolic complication.

Such differences seem to come from the difference in warfarin metabolism between the Easterners and Westerners. Japanese patients receiving warfarin therapy had a significantly greater body weight-normalised plasma unbound clearance of S-warfarin than white patients [41, 42]. Caucasian and Japanese patients who carried CYP2C9 variants possessed a lower unbound oral clearance for S-warfarin (decreased metabolic activity), thereby required a smaller daily dose of the drug [42]. In addition, Japanese possessing the wild-type promoter and coding sequences had significantly greater CYP2C9 activity than white patients with the corresponding genotype [43]. Recently, a pharmacological dose algorithm for warfarin that uses genotypes from two genes (VKORC1 and CYP2C9) and clinical variables was developed to predict the stable therapeutic dose [42]. Those 
Table 3. Medications that may potentiate GI bleeding (in alphabetical order)

\begin{tabular}{|c|c|c|c|}
\hline Drug & Half life & $\begin{array}{l}\text { Time of } \\
\text { action }\end{array}$ & Mechanism of action \\
\hline Abciximab & $\begin{array}{l}0.7 \text { hours (in } \\
\text { alpha), } 10 \text { hours }\end{array}$ & 0.5-2.5 hours & Nonspecific antagonist for glycoprotein IIb/IIIa receptor. \\
\hline $\begin{array}{l}\text { Anagrelide } \\
\text { hydrochloride }\end{array}$ & $\begin{array}{l}\text { (in beta) } \\
76 \text { hours }\end{array}$ & Long & $\begin{array}{l}\text { Reduction in platelet production resulting from a decrease in } \\
\text { megakaryocyte. }\end{array}$ \\
\hline Aspirin & $\begin{array}{l}0.25-19 \text { hours } \\
\text { (depends on } \\
\text { dose) }\end{array}$ & 0.5-5 hours & $\begin{array}{l}\text { Irreversibly acetylates and inactivates cyclooxygenase, and thereby } \\
\text { inhibits platelet production of thromboxane A2. }\end{array}$ \\
\hline Beraprost sodium & 1 hour & 0.5 hour & $\begin{array}{l}\text { Reversibly exacerbates adenylcyclase activation (reversible within } 8 \\
\text { hours). }\end{array}$ \\
\hline Clopidogrel & 7-8 hours & 2 hours & $\begin{array}{l}\text { Same with ticlopidine, but has less side effects such as severe } \\
\text { neutropenia and thrombotic thrombocytopenic purpura than } \\
\text { ticlopidine. }\end{array}$ \\
\hline Cilostazol & 11-13 hours & 3-6 hours & Inhibition of phosphoestrase (reversible within 48 hours). \\
\hline $\begin{array}{l}\text { Dilazep } \\
\text { dihydrochloride }\end{array}$ & 4 hours & 0.5-1 hour & Reversibly inhibits phosphoestrase. \\
\hline Dipyridamole & 1.7 hours & 2-3 hours & Reversibly inhibits phosphoestrase and inhibits uptake of adenosine. \\
\hline Ethyl icosapentate & $<24$ hours & Long & Irreversibly inhibits thromboxane A2 production. \\
\hline Heparin & $0.5-2.5$ hours & Immediately & $\begin{array}{l}\text { Activates antithrombin III, accerelates the rate of inhibiting clotting } \\
\text { enzymes, particulary thrombin and factor Xa. }\end{array}$ \\
\hline Ifenprodil tartate & 1.4 hour & Short & Inhibits binding to serotonin $5 \mathrm{HT} 2$ receptor. \\
\hline $\begin{array}{l}\text { Nonsteroidal anti- } \\
\text { inflammatory agents }\end{array}$ & $<24$ hours & 0.5 hours & Reversibly inhibit platelet cycloxygenase. \\
\hline Ozagrel sodium & 1.5 hour & Short & Inhibits enzymatic synthesis of thromboxane. \\
\hline $\begin{array}{l}\text { Sarpogrelate } \\
\text { hydrochloride }\end{array}$ & 0.7 hour & 1.5 hour & $\begin{array}{l}\text { Reversibly inhibits binding to serotonin } 5 \mathrm{HT} 2 \text { receptor as a selective } \\
\text { antagonist. }\end{array}$ \\
\hline Ticlopidine & 12.6 hours & 6 hours & $\begin{array}{l}\text { Irreversibly inhibits the binding of adenosine diphosphate to platelet } \\
\text { cell-surface adenosine diphosphate (P2) receptor, and the subsequent }\end{array}$ \\
\hline Tirofiban & 1.5-3 hours & 0.1 hour & $\begin{array}{l}\text { ADP-mediated activation of the glycoprotein IIb/IIIa receptor. } \\
\text { Specific antagonist for glycoprotein IIb/IIIa receptor. }\end{array}$ \\
\hline Trapidil & 2-4 hours & $0.5-2$ hours & $\begin{array}{l}\text { Reversibly inhibits phosphoestrase, reversibly inhibits thromboxane } \\
\text { A2 production. }\end{array}$ \\
\hline Triflusal & 0.5 hour & 24 hours & Inhibits platelet arachidonic acid metabolism. \\
\hline Warfarin & $36-42$ hours & $72-96$ hours & $\begin{array}{l}\text { Prohibit the synthesis of Vitamin } \mathrm{K} \text { dependent coagulation factor (II, } \\
\text { VII, IX, X) in the liver Vitamin } \mathrm{K} \text { is used as an antagonist. }\end{array}$ \\
\hline
\end{tabular}

Informations obtained at http://www.rxlist.com, http://kimsonline.co.kr, and http://www.druginfo.co.kr.

carrying the VKORC1 $1173 \mathrm{C} / \mathrm{C}$ wild-type allele needed higher unbound concentrations of S-warfarin to achieve a therapeutic anticoagulation response (reduced sensitivity), and a greater daily dose was required [42]. Apart from the genetic variability in determining the dose of warfarin, diet might play a role in bleeding time and in response to warfarin. Patients with high fish diets eat a lot of omega-3 fatty acid which inhibits thromboxane production. In addition, pa- 


\section{a}

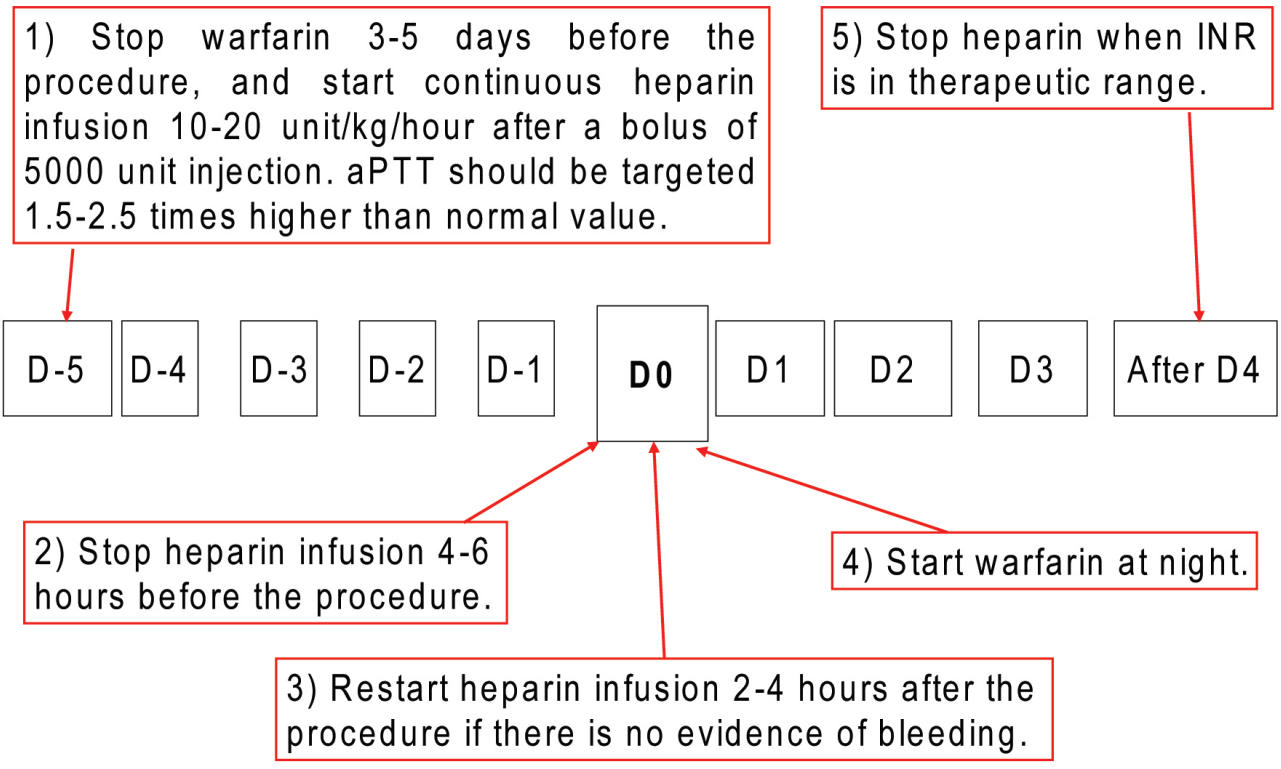

b

1) Stop warfarin $3-5$ days before the
procedure, and initiate low molecular weight
heparin $(\mathrm{LMWH})$.

5) Stop LMWH when INR is in therapeutic range.

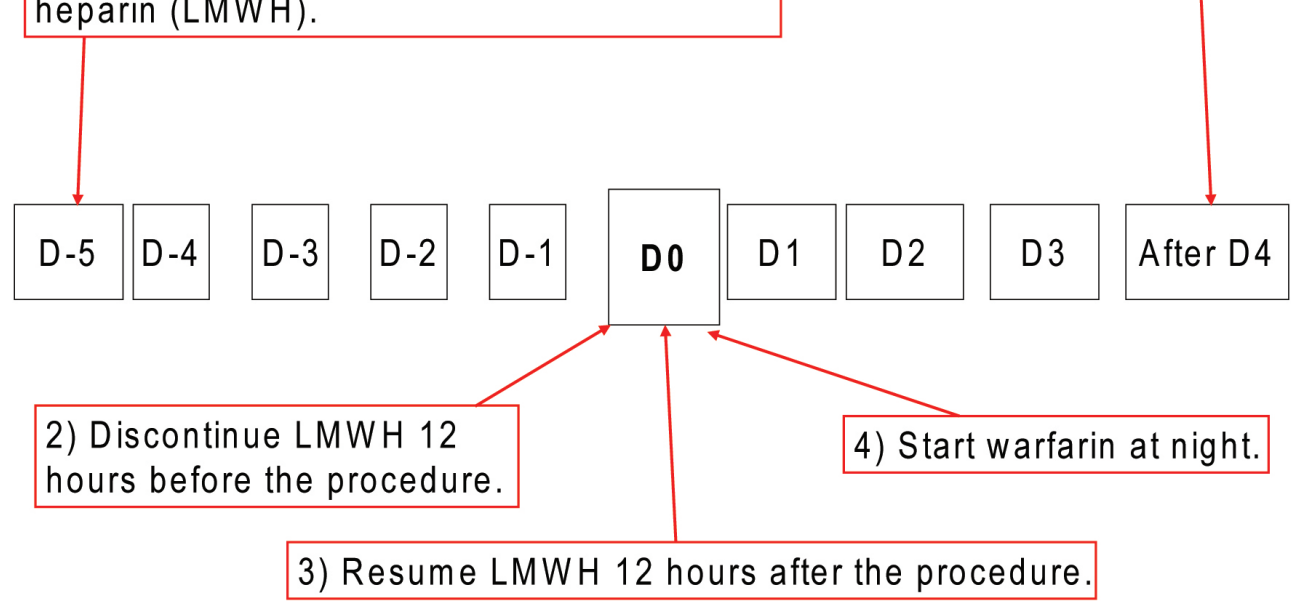

Figure 1. Recommendations on managing anticoagulants for high-risk patients undergoing high-risk procedures. (a) Warfarin substituted with intravenous heparin infusion. Warfarin should be stopped 3-5 days before the procedure, and be substituted with unfractionized heparin during the cessation period. (b) Warfarin substituted with subcutaneous heparin injection. Subcutaneous low molecular weighted heparin (LMWH) can be used instead of unfractionized heparin. Risk of thromboembolic complications must be carefully weighed against the increased risk of bleeding by maintaining anticoagulation.

tients with low vitamin $\mathrm{K}$ level would require smaller dose of warfarin. Recently, an algorithm was developed for estimating the appropriate warfarin dose that is based on both clinical and genetic data from a broad population base [44].

\section{Heparin}

Heparin should be stopped 4 to 6 hours before the procedure and restarted 2 to 6 hours later after the procedure if there is no evidence of bleeding (Fig. 1) [36]. LMWH con- 


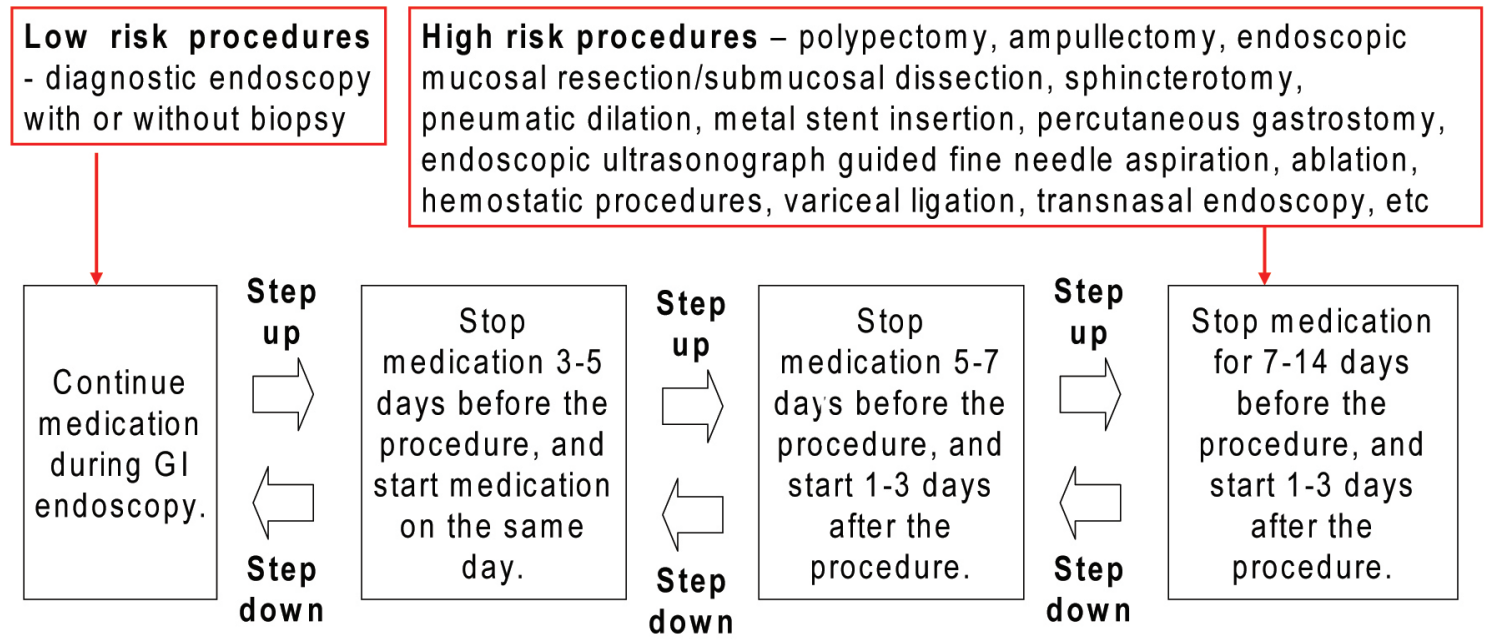

Step up if the patient is Easternist, taking combination therapy with anticoagulants or other antiplatelets, has a history of GI bleeding or ulcer disease, $H$. pylori infection, or other conditions that increase the risk of bleeding.

Step dow $\mathrm{n}$ if the patient is Westernist, has atrial fibrillation, venous thromboembolism, valvular heart disease and/or mechanical valve, ischemic heart disease and/or coronary artery stents, past history of thromboembolism, or other conditions that increase the risk of thromboembolism.

\begin{abstract}
Figure 2. Recommendation on managing antiplatelets for $\mathrm{Gl}$ endoscopy by risk stratification. For low-risk procedures, GI endoscopy could be performed without discontinuing the antiplatelets. If the patient is Easternist, taking dual therapy with anticoagulants or other antiplatelets, has a history of $\mathrm{Gl}$ bleeding or ulcer disease, $\mathrm{H}$. pylori infection, or other conditions that increase the risk of bleeding, cessation of drugs should be considered (marked as "Step up" with an arrow in the schema). For high-risk procedures with more than $1 \%$ of bleeding complication rate, cessation of antiplatelets should be considered at least 1 week before the procedure, and restarted when there is no evidence of bleeding. If the patient is Westernist, has atrial fibrillation, venous thromboembolism, valvular heart disease, mechanical valve, ischemic heart disease, coronary artery stents, past history of thromboembolism, or other conditions that increase the risk of thromboembolism, shorter cessation of antiplatelets should be considered (marked as "Step down" with an arrow in the schema). The degree of stepping up and down should be decided according to the number and severity of risk factors written above.
\end{abstract}

sisted of smaller fragments of heparin, has replaced heparin because of its advantages such as a better bioavailability and longer half-life after subcutaneous injection, dose-independent clearance, predictable anticoagulant response, lower risk of heparin-induced thrombocytopenia, and osteoporosis [45]. In addition, LMWH has been demonstrated to cause less bleeding that unfractionized heparin because it binds to platelets, and thus is less likely to interfere with the interaction between platelets and the vessel wall [45]. Moreover, an advantage of LMWH over unfractionated heparin is that perioperative conversion from warfarin therapy with LMWH can be carried out in the outpatient. However, lack of a readily available laboratory test for monitoring is a great disadvantage, since endoscopists cannot be certain of the amount of anticoagulant effect present at the time of procedure. Since antifactor Xa activity may persist up to 12 hours after a single subcutaneous injection, the best test to monitor activity is an antifactor Xa assay, but this takes a long process time $[3,45]$. LMWH is only partially reversible by protamine sulfate, and there is no proven evidence in the safety and effect for GI endoscopy $[46,47]$.

\section{Aspirin}

There are Western reports showing that the administration of aspirin at standard dosages does not significantly increase the risk of bleeding after an endoscopic biopsy, colon polypectomy, or endoscopic sphincterotomy [48-52]. However, aspirin is known to cause a significant GI bleeding after endoscopic procedures in the Easternists, and thus recommended to stop not only for polypectomy but even for a biopsy [6-8]. A retrospective study from Honkong is the only Asian study that encouraged polypectomy without 
Table 4. Summary on major differences between the East and West

\begin{tabular}{|c|c|c|}
\hline & East & West \\
\hline $\begin{array}{l}\text { Risk of } \\
\text { embolism }\end{array}$ & $\begin{array}{l}\text { Lower than the Westerners. } \\
\text { Common form is cerebrovascular variety that may lead } \\
\text { to death or disability. }\end{array}$ & $\begin{array}{l}\text { Higher than the Easterners. } \\
\text { Common form is cardiovascular variety } \\
\text { including deep vein thrombosis. }\end{array}$ \\
\hline $\begin{array}{l}\text { Risk of } \\
\text { bleeding }\end{array}$ & $\begin{array}{l}\text { Higher than the Westeners due to different drug } \\
\text { metabolism (greater body weight-normalized plasma } \\
\text { unbound clearance of drug) and higher rate of } H \text {. pylori } \\
\text { infection. }\end{array}$ & $\begin{array}{l}\text { Lower than the Easterners. } \\
\text { Tolerates well with low-risk endoscopic } \\
\text { procedures during antiplatelet and/or } \\
\text { anticoagulant medications. }\end{array}$ \\
\hline $\begin{array}{l}\text { Managing } \\
\text { warfarin }\end{array}$ & $\begin{array}{l}\text { Lower international normalized ratio value }(1.6-2.6) \\
\text { than the Westerners are appropriate for prophylaxis of } \\
\text { thromboembolism. }\end{array}$ & $\begin{array}{l}\text { Tolerates well with low-risk procedures } \\
\text { (endoscopic biopsy) without significant } \\
\text { bleeding. }\end{array}$ \\
\hline $\begin{array}{l}\text { Managing } \\
\text { aspirin }\end{array}$ & $\begin{array}{l}\text { Lower dose is recommended than the Westerners due to } \\
\text { higher risk of bleeding. }\end{array}$ & $\begin{array}{l}\text { Tolerates well with few high-risk } \\
\text { procedures (endoscopic sphincterotomy } \\
\text { and colon polypectomy) without significant } \\
\text { bleeding. }\end{array}$ \\
\hline
\end{tabular}

cessation of aspirin [50]. Of their 1657 subjects who underwent colon polypectomies, 127 subjects were taking aspirin, and $4.72 \%(6 / 127)$ revealed post-polypectomy bleeding. Notably, another study from Hongkong showed that aspirin therapy increased the risk of postsphincterotomy bleeding [53]. They reported that withholding aspirin for one week before endoscopic sphincterotomy did not seem to decrease the risk of post-sphincterotomy bleeding, because aspirin induces a long-lasting functional defect in platelets. These opposite results from Hongkong made problem unsolved, because the risk of postpolypectomy bleeding $(1.4 \%)$ is known to be identical to that of postpolypectomy bleeding $(1.4 \%)[54,55]$. Therefore, it is not strange that most of the Eastern endoscopists stop aspirin for a polypectomy [1].

Actual effects of aspirin are likely to differ by race and ethnicity. Although Western reports showed that aspirin does not affect GI bleeding time [48], significant prolongation was noted in colonic bleeding time after aspirin ingestion in Easternists [56]. Indeed, the threshold of antiplatelet therapy for Asian populations is considered to be 2 to 5 times higher than those for the US population, because of higher risks of hemorrhagic complications [57]. In addition, it has been reported that prevalences of gastrodeuodenal mucosal injury and bleeding are higher in Japanese receiving antiplatelet agents [58]. The higher estimated incidence of major GI bleeding might be related to the higher prevalence of $H$. pylori infection in this population. In a study case-control study of 695 consecutive users of low-dose aspirin with upper GI bleeding, H. pylori infection was identified as an independent risk factor of upper GI bleeding [59]. Besides, prophylaxis with a PPI effectively prevents recurrent upper GI bleeding with low-dose aspirin, despite failure of $H$. $p y$ - lori eradication and concomitant use of NSAIDs [32]. Taken altogether, recommended dose of aspirin should be smaller in the Easternists because low-dose aspirin $(75-150 \mathrm{mg})$ is effective, and because high-dose aspirin (> 100-200 mg) produces double rate of bleeding compared with low-dose aspirin $(75-100 \mathrm{mg})$ per day $[24,57]$.

Notably, there were few Western studies that showed bleeding risks during aspirin intake. Minor bleeding occurred after biopsy or polypectomy at EGD or colonoscopy in 20 of $320(6.3 \%)$ patients who had recently consumed aspirin or NSAIDs compared with 8 of $374(2.1 \%)$ patients who had not [49]. Even in low-dose aspirin, major right sided colonic hemorrhage occurred after hot biopsy of diminutive colonic polyps [60]. Among elderly patients, the odd ratios of bleeding with daily doses of aspirin of 75,150 , and $300 \mathrm{mg}$ were $2.3,3.2$, and 3.9, respectively [61]. In this study, the use of low-dose aspirin was associated with a two to fourfold greater risk of upper GI event, which is not reduced by the use of buffered or enteric-coated preparations [32, 61].

\section{Non-aspirin NSAIDs}

Both the Eastern and Western endoscopists do not stop NSAIDs for endoscopic procedure [1], NSAIDs does not appear to prolong mucosal bleeding time [62], and does not increase the incidence of major bleeding [49]. Among nonaspirin-NSAIDs, aceclofenac had the lowest risk of upper GI bleeding, whereas ketorolac had the highest [63]. In this study, rofecoxib increased the risk of upper GI bleeding, whereas celecoxib, paracetamol or concomitant use of a PPI with an NSAID presented no increased risk. However, when combined with low-dose aspirin, the differences between non-selective NSAIDs and coxibs tend to disappear [63]. 
An apparent interaction was found between low-dose aspirin and use of non-aspirin-NSAIDs, coxibs or thienopyridines, which increased risk of upper GI bleeding. Treatment with either non-aspirin antiplatelet or cardioprotective aspirin has a similar risk of upper GI bleeding [32, 63].

Platelet cell-surface adenosine diphosphate receptor antagonist (ticlopidine, clopidogrel, dipyridamole)

Platelet cell-surface adenosine diphosphate receptor antagonist includes thinopyridines (ticlopidine and clopidogrel) and dipyridamole. Ticlopidine and clopidogrel are recommended to be ceased 7 to 10 days before the procedure $[3,14]$. In a recent European publication, clopidogrel is recommended to be ceased only for the high-risk procedures [5]. Besides, Japanese studies recommends 3 days of cessation period for aspirin, 5 days for ticlopidine, and 7 days for dual aspirin and ticlopidine therapy even for a biopsy [6, 64, 65]. Notably, dipyridamole does not increase bleeding risk, even with a dual antiplatelet therapy with aspirin [66].

Ticlopidine are more likely to induce endoscopic evidence of mucosal damage than patients taking aspirin or NSAIDs [28]. Besides, substitution of clopidogrel for aspirin is not recommended to reduce the risk of recurrent ulcer bleeding in high-risk patients, because their anti-angiogenic effects may impair healing of gastric erosions or small ulcerations that develop from other medications or $H$. pylori infection [32]. In summary, to minimize GI bleeding, history of ulcer and other GI risk factors should be assessed first, followed by test for $H$. pylori and treat if infected. PPI reduces the bleeding risk in most cases $[32,63]$.

Glycoprotein IIb/IIIa receptor antagonist (etifibatide, abciximab, tirofiban)

Glycoprotein IIb/IIIa receptor antagonists are intravenously administered drugs given as a bolus followed by a continous infusion in acute coronary syndrome. There is no guideline for glycoprotein IIb/IIIa receptor antagonists, and it seems that a considerable number of endoscopists are unaware of these drugs [1]. Platelet functions are known to be recovered within 4 hours after the cessation of tirofiban and eptifibatide, whereas 24 hours are required for abciximab [12]. The antiplatelet effects can be partially reversed by platelet infusions or desmopressin (DDAVP) [3].

Collaboration between the endoscopist and physicians prescribing drugs

Collaboration between the endoscopists and other engaged physicians (cardiologists, neurologists, surgeons, or general practitioners) are important to balance the risks of bleeding and thrombosis when deciding the cessation of antiplatelets and/or anticoagulants. Such collaboration will help endoscopists to make decision more appropriately by minimizing cardiovascular concerns. However, it seems that only $61.9 \%$ of Eastern endoscopists and $56.0 \%$ of Western endoscopists usually consult with the referring physician who prescribed the medications [1]. Reasons why many endoscopists do not consult primary care physicians about management of antiplatelet and/or anticoagulation medications might be related to (1) patient factors; (2) endoscopist factor; and (3) external factor [67]. First, some people take aspirin simply for cardioprotective reasons without significant disease, and thus endoscopists do not consult primary physicians in such situations. Second, endoscopists usually do not perform high-risk endoscopic procedures on patients taking warfarin except in emergency situations. That is, endoscopists usually defer elective procedures in high-risk patients. Third, there is no appropriate guideline that covers the exact situation in each patient. Personal experience seems to be more powerful driver of practice than published literature as noted in our survey [1].

Not knowing the importance of collaboration and measuring the risks/benefits in each individual patient on a caseby-case basis, it would be very difficult to estimate the risks. A schema weighting the risk of bleeding and thromboembolism might be suggested (Fig. 2) considering the differences between the East and West (Table 4).

\section{Conclusions}

There are significant differences of opinion and practice patterns between Eastern and Western endoscopists based on significant differences on embolism, bleeding, and drug metabolism. The ratio of cerebral infarction to cardiovascular thromboembolism is different, and the recommended doses of antiplatelet and anticoagulant are smaller in the East due to different drug metabolism. The risk/benefit ratio of antiplatelets and anticoagulants may differ across population, and thus higher bleeding tendency due to higher concentration of drugs in Easterners should be considered.

Increased use of anticoagulants and antiplatelets will keep this as an argument not only to the GI endoscopists but also to the physicians prescribing these drugs. Both the concerns of endoscopists who want to stop medications to lessen the risk of hemorrhage, and the concerns of prescribing physicians who want to continue medications because of a fear of thromboembolic events, should always be considered based on patient's individual characteristics such as a racial difference. Being aware of such wide variation between the East and West will be helpful in weighing the risk of bleeding and thromboembolism, when managing antiplatelets and anticoagulants for GI endoscopy.

\section{Acknowledgements}

This work was supported by the Korea Research Foun- 
dation Grant funded by the Korean Government (KRF 2008531-E00030). The author declares no conflict of interests related to this article.

\section{References}

1. Lee SY, Tang SJ, Rockey DC, Weinstein D, Lara L, Sreenarasimhaiah J, Choi KW. Managing anticoagulation and antiplatelet medications in GI endoscopy: a survey comparing the East and the West. Gastrointest Endosc 2008;67:1076-1081.

2. Eisen GM, Baron TH, Dominitz JA, Faigel DO, Goldstein JL, Johanson JF, Mallery JS, et al. Guideline on the management of anticoagulation and antiplatelet therapy for endoscopic procedures. Gastrointest Endosc 2002;55:775-779.

3. Zuckerman MJ, Hirota WK, Adler DG, Davila RE, Jacobson BC, Leighton JA, Qureshi WA, et al. ASGE guideline: the management of low-molecular-weight heparin and nonaspirin antiplatelet agents for endoscopic procedures. Gastrointest Endosc 2005;61:189-194.

4. Napoleon B, Boneu B, Maillard L, Samama CM, Schved JF, Gay G, Ponchon T, et al. Guidelines of the French Society for Digestive Endoscopy (SFED). Endoscopy 2006;38:632-638.

5. Veitch AM, Baglin TP, Gershlick AH, Harnden SM, Tighe R, Cairns S. Guidelines for the management of anticoagulant and antiplatelet therapy in patients undergoing endoscopic procedures. Gut 2008;57:1322-1329.

6. Ogoshi K, Kaneko E, Tada M, Mitsu T, Yoshino J, Yahagi $\mathrm{N}$, Goto N. The management of anticoagulation and antiplatelet therapy for endoscopic procedures. Gastroenterol Endosc 2005;47:2691-2695.

7. Ishizawa T, Tamai Y, Tamaki H, Yamagata K, Mikami T, Sasaki S, Fukuda S, et al. A survey of the relationship between the cessation period of anti-platelet agents on the invasive endoscopic procedure. Gastroenterol Endosc 2006;48:1102-1108.

8. Fujishiro M, Oda I, Yamamoto Y, Akiyama J, Ishii N, Kakushima N, Fujiwara J, et al. Multi-center survey regarding the management of anticoagulation and antiplatelet therapy for endoscopic procedures in Japan. $\mathrm{J}$ Gastroenterol Hepatol 2009;24:214-218.

9. Gerson LB, Gage BF, Owens DK, Triadafilopoulos G. Effect and outcomes of the ASGE guidelines on the periendoscopic management of patients who take anticoagulants. Am J Gastroenterol 2000;95:1717-1724.

10. Goel A, Barnes CJ, Osman H, Verma A. National survey of anticoagulation policy in endoscopy. Eur J Gastroenterol Hepatol 2007;19:51-56.

11. Kimchi NA, Broide E, Scapa E, Birkenfeld S. Antiplatelet therapy and the risk of bleeding induced by gastrointestinal endoscopic procedures. A systematic review of the literature and recommendations. Digestion 2007;75:36-45.

12. Makar GA, Ginsberg GG. Therapy insight: approaching endoscopy in anticoagulated patients. Nat Clin Pract Gastroenterol Hepatol 2006;3:43-52.

13. Mosler P, Mergener K, Denzer U, Kiesslich R, Galle PR, Kanzler S. Current practice in managing patients on anticoagulants and/or antiplatelet agents around the time of gastrointestinal endoscopy -- a nation-wide survey in Germany. Z Gastroenterol 2004;42:1289-1293.

14. Hittelet A, Deviere J. Management of anticoagulants before and after endoscopy. Can J Gastroenterol 2003;17:329-332.

15. Kadakia SC, Angueira CE, Ward JA, Moore M. Gastrointestinal endoscopy in patients taking antiplatelet agents and anticoagulants: survey of ASGE members. American Society for Gastrointestinal Endoscopy. Gastrointest Endosc 1996;44:309-316.

16. Lee SY. The type of the patient should be considered on discontinuation of anticoagulant and antiplatelet therapy. Gut 2009;58:153-154; author reply 154.

17. Lee SY, Chang DK, Park DI, Jeen YT, Lee SH, Shin JE, Park DH, et al. Multicenter survey on gastrointestinal endoscopic examination during anticoagulation or antiplatelet medications. Korean J Gastrointest Endosc 2006;33(S2):169-170.

18. Blacker DJ, Wijdicks EF, McClelland RL. Stroke risk in anticoagulated patients with atrial fibrillation undergoing endoscopy. Neurology 2003;61:964-968.

19. Collet JP, Montalescot G, Blanchet B, Tanguy ML, Golmard JL, Choussat R, Beygui F, et al. Impact of prior use or recent withdrawal of oral antiplatelet agents on acute coronary syndromes. Circulation 2004;110:2361-2367.

20. Ferrari E, Benhamou M, Cerboni P, Marcel B. Coronary syndromes following aspirin withdrawal: a special risk for late stent thrombosis. J Am Coll Cardiol 2005;45:456-459.

21. Dunn AS, Turpie AG. Perioperative management of patients receiving oral anticoagulants: a systematic review. Arch Intern Med 2003;163:901-908.

22. Garcia DA, Regan S, Henault LE, Upadhyay A, Baker J, Othman M, Hylek EM. Risk of thromboembolism with short-term interruption of warfarin therapy. Arch Intern Med 2008;168:63-69.

23. Kuwada SK, Balm R, Gostout CJ. The risk of withdrawing chronic anticoagulation because of acute GI bleeding. Am J Gastroenterol 1996;91:1116-1119.

24. Shinohara Y. Regional differences in incidence and management of stroke - is there any difference between Western and Japanese guidelines on antiplatelet therapy? Cerebrovasc Dis 2006;21 Suppl 1:17-24.

25. Sekikawa A, Kuller LH, Ueshima H, Park JE, Suh I, Jee SH, Lee HK, et al. Coronary heart disease mortality trends in men in the post World War II birth cohorts aged 
35-44 in Japan, South Korea and Taiwan compared with the United States. Int J Epidemiol 1999;28:1044-1049.

26. Lanas A, Garcia-Rodriguez LA, Arroyo MT, Gomollon F, Feu F, Gonzalez-Perez A, Zapata E, et al. Risk of upper gastrointestinal ulcer bleeding associated with selective cyclo-oxygenase-2 inhibitors, traditional nonaspirin non-steroidal anti-inflammatory drugs, aspirin and combinations. Gut 2006;55:1731-1738.

27. Hylek EM. Complications of oral anticoagulant therapy: bleeding and nonbleeding, rates and risk factors. Semin Vasc Med 2003;3:271-278.

28. Sheikh RA, Romano PS, Prindiville TP, Yasmeen S, Trudeau W. Endoscopic evidence of mucosal injury in patients taking ticlopidine compared with patients taking aspirin/nonsteroidal antiinflammatory drugs and controls. J Clin Gastroenterol 2002;34:529-532.

29. Wilcox CM, Truss CD. Gastrointestinal bleeding in patients receiving long-term anticoagulant therapy. Am J Med 1988;84:683-690.

30. Choudari CP, Rajgopal C, Palmer KR. Acute gastrointestinal haemorrhage in anticoagulated patients: diagnoses and response to endoscopic treatment. Gut 1994;35:464466.

31. Obara K. Incidents associated with endoscopic procedures and their prevention. Endosc Digest 2008;20:16331638.

32. Bhatt DL, Scheiman J, Abraham NS, Antman EM, Chan FK, Furberg CD, Johnson DA, et al. ACCF/ACG/AHA 2008 expert consensus document on reducing the gastrointestinal risks of antiplatelet therapy and NSAID use. Am J Gastroenterol 2008;103:2890-2907.

33. Ananthasubramaniam K, Beattie JN, Rosman HS, Jayam V, Borzak S. How safely and for how long can warfarin therapy be withheld in prosthetic heart valve patients hospitalized with a major hemorrhage? Chest 2001;119:478-484.

34. Kimmey MB. Cardioprotective effects and gastrointestinal risks of aspirin: maintaining the delicate balance. Am J Med 2004;117 Suppl 5A:72S-78S.

35. Chan FK, Chung SC, Suen BY, Lee YT, Leung WK, Leung VK, Wu JC, et al. Preventing recurrent upper gastrointestinal bleeding in patients with Helicobacter pylori infection who are taking low-dose aspirin or naproxen. N Engl J Med 2001;344:967-973.

36. Lee SY. Polypectomy in patients taking anticoagulants. Intestinal Res 2008;6(S2):129-135.

37. Friedland S, Soetikno R. Colonoscopy with polypectomy in anticoagulated patients. Gastrointest Endosc 2006;64:98-100.

38. Timothy SK, Hicks TC, Opelka FG, Timmcke AE, Beck DE. Colonoscopy in the patient requiring anticoagulation. Dis Colon Rectum 2001;44:1845-1848; discussion, 1848-1849.

39. Yasaka M, Minematsu K, Yamaguchi T. Optimal inten- sity of international normalized ratio in warfarin therapy for secondary prevention of stroke in patients with nonvalvular atrial fibrillation. Intern Med 2001;40:11831188.

40. Yamaguchi T. Optimal intensity of warfarin therapy for secondary prevention of stroke in patients with nonvalvular atrial fibrillation : a multicenter, prospective, randomized trial. Japanese Nonvalvular Atrial FibrillationEmbolism Secondary Prevention Cooperative Study Group. Stroke 2000;31:817-821.

41. Takahashi H, Wilkinson GR, Caraco Y, Muszkat M, Kim RB, Kashima T, Kimura S, et al. Population differences in S-warfarin metabolism between CYP2C9 genotypematched Caucasian and Japanese patients. Clin Pharmacol Ther 2003;73:253-263.

42. Takahashi H, Wilkinson GR, Nutescu EA, Morita T, Ritchie MD, Scordo MG, Pengo V, et al. Different contributions of polymorphisms in VKORC1 and CYP2C9 to intra- and inter-population differences in maintenance dose of warfarin in Japanese, Caucasians and AfricanAmericans. Pharmacogenet Genomics 2006;16:101110.

43. Takahashi H, Ieiri I, Wilkinson GR, Mayo G, Kashima T, Kimura S, Otsubo K, et al. 5'-Flanking region polymorphisms of CYP2C9 and their relationship to S-warfarin metabolism in white and Japanese patients. Blood 2004;103:3055-3057.

44. Klein TE, Altman RB, Eriksson N, Gage BF, Kimmel SE, Lee MT, Limdi NA, et al. Estimation of the warfarin dose with clinical and pharmacogenetic data. N Engl J Med 2009;360:753-764.

45. Weitz JI, Hirsh J, Samama MM. New antithrombotic drugs: American College of Chest Physicians EvidenceBased Clinical Practice Guidelines (8th Edition). Chest 2008;133:234S-256S.

46. Jafri SM, Mehta TP. Periprocedural management of anticoagulation in patients on extended warfarin therapy. Semin Thromb Hemost 2004;30:657-664.

47. Goldstein JL, Larson LR, Yamashita BD, Fain JM, Schumock GT. Low molecular weight heparin versus unfractionated heparin in the colonoscopy peri-procedure period: a cost modeling study. Am J Gastroenterol 2001;96:2360-2366.

48. O’Laughlin JC, Hoftiezer JW, Mahoney JP, Ivey KJ. Does aspirin prolong bleeding from gastric biopsies in man? Gastrointest Endosc 1981;27:1-5.

49. Shiffman ML, Farrel MT, Yee YS. Risk of bleeding after endoscopic biopsy or polypectomy in patients taking aspirin or other NSAIDS. Gastrointest Endosc 1994;40:458-462.

50. Hui AJ, Wong RM, Ching JY, Hung LC, Chung SC, Sung JJ. Risk of colonoscopic polypectomy bleeding with anticoagulants and antiplatelet agents: analysis of 1657 cases. Gastrointest Endosc 2004;59:44-48. 
51. Yousfi M, Gostout CJ, Baron TH, Hernandez JL, Keate R, Fleischer DE, Sorbi D. Postpolypectomy lower gastrointestinal bleeding: potential role of aspirin. Am J Gastroenterol 2004;99:1785-1789.

52. Freeman ML, Nelson DB, Sherman S, Haber GB, Herman ME, Dorsher PJ, Moore JP, et al. Complications of endoscopic biliary sphincterotomy. N Engl J Med 1996;335:909-918.

53. Hui CK, Lai KC, Yuen MF, Wong WM, Lam SK, Lai CL. Does withholding aspirin for one week reduce the risk of post-sphincterotomy bleeding? Aliment Pharmacol Ther 2002;16:929-936.

54. Waye JD, Lewis BS, Yessayan S. Colonoscopy: a prospective report of complications. J Clin Gastroenterol 1992; 15:347-351.

55. Sherman S, Ruffolo TA, Hawes RH, Lehman GA. Complications of endoscopic sphincterotomy. A prospective series with emphasis on the increased risk associated with sphincter of Oddi dysfunction and nondilated bile ducts. Gastroenterology 1991;101:1068-1075.

56. Nakajima H, Takami H, Yamagata K, Kariya K, Tamai Y, Nara H. Aspirin effects on colonic mucosal bleeding: implications for colonic biopsy and polypectomy. Dis Colon Rectum 1997;40:1484-1488.

57. Morimoto T, Fukui T, Lee TH, Matsui K. Application of U.S. guidelines in other countries: aspirin for the primary prevention of cardiovascular events in Japan. Am J Med 2004;117:459-468.

58. Yamamoto T, Sanaka M, Nagasawa K, Abe K, Fukami M, Nakayama S, Tsuchiya A, et al. Gastroduodenal mucosal injury in patients on antiplatelet therapy. Thromb Res 2007;120:465-469.

59. Lanas A, Fuentes J, Benito R, Serrano P, Bajador E, Sainz R. Helicobacter pylori increases the risk of upper gastrointestinal bleeding in patients taking low-dose aspirin. Aliment Pharmacol Ther 2002;16:779-786.
60. Dyer WS, Quigley EM, Noel SM, Camacho KE, Manela F, Zetterman RK. Major colonic hemorrhage following electrocoagulating (hot) biopsy of diminutive colonic polyps: relationship to colonic location and low-dose aspirin therapy. Gastrointest Endosc 1991;37:361-364.

61. Weil J, Colin-Jones D, Langman M, Lawson D, Logan R, Murphy M, Rawlins M, et al. Prophylactic aspirin and risk of peptic ulcer bleeding. BMJ 1995;310:827830 .

62. Basson MD, Panzini L, Palmer RH. Effect of nabumetone and aspirin on colonic mucosal bleeding time. Aliment Pharmacol Ther 2001;15:539-542.

63. Lanas A, Garcia-Rodriguez LA, Arroyo MT, Bujanda L, Gomollon F, Forne M, Aleman S, et al. Effect of antisecretory drugs and nitrates on the risk of ulcer bleeding associated with nonsteroidal anti-inflammatory drugs, antiplatelet agents, and anticoagulants. Am J Gastroenterol 2007;102:507-515.

64. Tamai Y, Komatsu T, Takami H, Nakajima H, Fukuda S, Munakata A. The management of antiplatelet therapy for endoscopic procedures - the optimal cessation period of antiplatelet therapy for Japanese. Gastroenterol Endosc 2008;50:2531-2539

65. Komatsu T, Tamai Y, Takami H, Yamagata K, Fukuda S, Munakata A. Study for determination of the optimal cessation period of therapy with anti-platelet agents prior to invasive endoscopic procedures. J Gastroenterol 2005;40:698-707.

66. Diener HC, Cunha L, Forbes C, Sivenius J, Smets P, Lowenthal A. European Stroke Prevention Study. 2. Dipyridamole and acetylsalicylic acid in the secondary prevention of stroke. J Neurol Sci 1996;143:1-13.

67. Lee SY, Tang SJ, Rockey DC. The management of antiplatelets in elective GI endoscopies: a collaboration between the endoscopists and the cardiologist. Gastrointest Endosc 2009;69:185-186. 